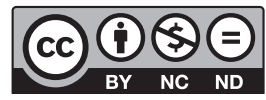

Estudos Teológicos foi licenciado com uma Licença Creative Commons Atribuição - NãoComercial - SemDerivados 3.0 Não Adaptada

http://dx.doi.org/10.22351/et.v58i2.3483

\title{
"TUDO ISSO É ADORNO PARA O LUGAR..." O grande projeto diaconal e Caritativo de Basílio de Cesareia ${ }^{1}$
}

\author{
"All this is a great improvement to the place..." \\ Basileios of Cesarea's Large-Scale Project of Welfare and Charity
}

\begin{abstract}
Andreas Müller²
Resumo: A chamada Basilíada, fundada por Basílio Magno antes de 370, é caracterizada como maravilha do mundo por Gregório de Nazianzo. A importância dessa instituição se baseia no fato de ter sido hospedaria, casa para pessoas pobres e hospital no marco da vida monástica. $\mathrm{O}$ arquétipo da Basilíada provavelmente deve ser identificado como os monastérios pacomianos no Egito, que ofereciam uma combinação semelhante de várias instituições. O ex-soldado Pacômio pode ter sido influenciado na criação desse novo tipo de convento a partir do leiaute dos acampamentos militares romanos. O valetudinarium desses acampamentos provavelmente serviu de inspiração para os hospitais dos monastérios. Basílio concebia o mundo inteiro como um monastério. Por isso organizou os subúrbios de Cesareia à imagem de um convento. Entretanto, ele não criou novas formas de instituições. A interpretação da Basilíada como maravilha do mundo é compreensível, pois oferecia uma combinação nova de elementos institucionais antigos com a interpretatio christiana da natureza humana. Aos pobres, forasteiros e doentes se oferecia a possibilidade de se encontrar com o próprio Deus na Basilíada.
\end{abstract}

Palavras-chave: Basílio de Cesareia. Basilíada. Diaconia. Caridade. Bem-Estar Social.

Abstract: The so-called Basileias, founded by Basileios the Great before 370, was characterized by Gregory Nazianzen as a Wonder of the World. The importance of this institution is based on the fact of having been a hostel, a house for poor people and a hospital in the mould of monastic life. The archetype of the Basileias probably has to be identified as the Pachomian monasteries in Egypt that offered a similar combination

1 O artigo foi recebido em 14 de outubro de 2018 e aprovado em 17 de outubro de 2018 com base nas avaliações dos pareceristas ad hoc.

Publicado originalmente, numa versão mais extensa, especialmente quanto às notas, como "All das ist Zierde für den Ort..." Das diakonisch-karitative Großprojekt des Basileios von Kaisareia. Zeitschrift für Antikes Christentum, Berlin, v. 13, n. 3, p. 452-474, 2010. Trad. Luís Marcos Sander, com financiamento do PROEX/CAPES.

2 Doutor em Teologia pela Universidade de Heidelberg e livre-docente em História da Igreja pela Universidade de Munique, Alemanha. Professor titular de História da Igreja e do Cristianismo no Primeiro Milênio na Faculdade de Teologia da Universidade de Kiel. Contato: AMueller@kg.uni-kiel.de 
of varied institutions. The former soldier Pachomius could have been influenced in the creation of this new type of convent by the layout of Roman military camps. The valetudinarium of these camps probably served as inspiration for the monasteries' hospitals. Basileios conceived the whole world as a monastery. Thus, he organized the suburbs of Cesareia in the image of a convent. However, he did not create new forms of institutions. The interpretation of the Basileias as Wonder of the World is understandable as it offered a new combination of ancient institutional elements with the interpretatio christiana of the human nature. To the poor, the strangers and the sick was offered a possibility of encounter with Godself in the Basileias.

Keywords: Basileios of Cesarea. Basileias. Diakonia. Charity. Welfare.

\section{Introdução}

Ainda no século IV d.C. se localizou uma maravilha do mundo na Ásia Menor: no discurso memorial para seu amigo Basílio de Cesareia, Gregório de Nazianzo falou de tal maravilha ao descrever a Basilíada, que deve esse nome a seu fundador. Ela merece atenção ainda nos dias de hoje, não só por causa da pessoa de Basílio, que, como se sabe, representa uma figura central da história do cristianismo da Antiguidade tardia. Embora Gregório de Nazianzo tenha estimado muito seu colega de estudos Basílio, já para ele a instituição situada diante dos portões da metrópole da província da Capadócia também era digna de nota de modo geral, como grande projeto diaconal e caritativo que era novo em sua forma.

No século IV/V d.C., a Basilíada foi objeto de grande atenção. Ainda hoje ela não falta em nenhuma exposição abrangente da história da diaconia e dos hospitais. Por isso vale a pena se ocupar de modo mais detalhado com esse empreendimento caracterizado como maravilha do mundo. Isso se justifica mais ainda porque ainda não se escreveu uma história diferenciada da diaconia do cristianismo na Antiguidade tardia que esteja no nível da pesquisa histórica atual. ${ }^{3}$ No que segue, pretendo oferecer um recorte central de tal exposição e, com isso, assentar uma segunda pedra fundamental para o projeto de uma exposição abrangente sobre a diaconia e assistência no cristianismo da Antiguidade e da Antiguidade tardia. ${ }^{4}$ Ao fazer isso, utilizo, em termos gerais, uma abordagem da história da cultura, mas que leva em consideração particularmente aspectos teológicos da história da diaconia.

Inicialmente, refletirei sobre as questões de historiadores da Antiguidade, especialistas em bizantinismo e historiadores da medicina: por conseguinte, será examinado o perfil institucional da Basilíada. Na segunda parte da contribuição, abordarei a questão de possíveis modelos históricos dela. Em um terceiro passo, será tematizada a

3 Afinal, a última visão panorâmica da história da diaconia na Antiguidade e Antiguidade tardia provém, em sua $2^{\mathrm{a}}$ edição, do ano de 1895 .

4 Um primeiro produto de meu estudo da história da diaconia no cristianismo da Antiguidade tardia é a seguinte publicação: MÜLLER, Andreas. Die Christianisierung staatlicher Wohlfahrtsinstitutionen im spätantiken Rom am Beispiel von S. Maria in Cosmedin. Zeitschrift für Kirchengeschichte, v. 120, p. 160-186, 2009. 
inserção dessa instituição na teologia dos famosos padres capadócios, que possibilita uma compreensão correta da importância e do significado da entidade.

\section{O perfil institucional da Basilíada segundo as fontes da Antiguidade tardia}

As mais detalhadas descrições ${ }^{5}$ da Basilíada são oferecidas pelo próprio $\mathrm{Ba}-$ sílio. ${ }^{6}$ Em uma carta escrita provavelmente antes de 370 d.C. (Epistula 94) ${ }^{7}$, ele se dirigiu ao governador recém-instalado da província romana da Capadócia chamado Elias. Na carta, Basílio justificou seu empreendimento ${ }^{8}$ : segundo ela, no centro se encontrava uma casa de oração esplendidamente decorada, e, em torno dela, uma residência para o diretor e alojamentos para os "servidores da divindade". Também o próprio governador e seu séquito poderiam hospedar-se ali. Possivelmente se tratava de alojamentos para uma comunidade conventual. ${ }^{9}$ Substancialmente, porém, a instituição era definida por hospedarias para viajores e instalações para doentes. Uma vasta infraestrutura estava prevista para a assistência aos doentes: antes de mais nada, "enfermeiros"10 e médicos ${ }^{11}$, mas também animais de carga e acompanhantes. Além

5 A mais minuciosa exposição se encontra, em associação com numerosas referências bibliográficas, mais recentemente em KOSCHORKE, Klaus. Spuren der alten Liebe: Studien zum Kirchenbegriff des Basilius von Caesarea. Freiburg (Schweiz): Universitätsverlag, 1991. p. 306-311.

6 No que se segue, só levo em consideração fontes que falem diretamente da Basilíada.

7 Cf. Bas., ep. 94 (CUFr, v. 1, 204-207 Courtonne; especialmente 205,25-206,44). Quanto à datação de Bas., ep. 94, cf. BASILIUS VON CAESAREA. Briefe: übersetzt, eingeleitet und erläutert von W.-D. Hauschild. Stuttgart, 1990. v. 1, p. 218, nota 407; além disso, ROUSSEAU, Philip. Basil of Caesarea. Berkeley: University of California, 1994. p. 139s; VOLK, Robert. Gesundheitswesen und Wohltätigkeit im Spiegel der byzantinischen Klostertypika. München, 1983. p. 39, por sua vez, data a fundação da Basilíada só em 372/373. Ele argumenta, apoiando-se em GIET, Stanislas. Les idées et l'action sociales de Saint Basile. Paris: Lecoffre, 1941, com Bas., ep. 176, com a qual Basílio teria convidado Anfilóquio de Icônio para a consagração. Essa suposição, porém, de modo algum pode ser depreendida inequivocamente dessa carta. Também as reflexões de Hauschild sobre a datação de ep. 94 são convincentes.

8 Neste contexto, Basílio não tinha, de modo algum, conflitos com o próprio governador, como CRISLIP, Andrew T. From Monastery to Hospital: Christian Monasticism and the Transformation of Health Care in Late Antiquity. Ann Arbor: The University of Michigan, 2005. p. 103-133, p. 109, afirma erroneamente. Quanto a seus adversários, veja abaixo.

9 Essa é a opinião de KNORR, Uwe W. Basilius der Große: Sein Beitrag zur christlichen Durchdringung Kleinasiens. 1968. Tese (Doutorado) - Tübingen, 1968. v. 1, p. 101s; BASILIUS, 1990, p. 219, nota 412; STEIDLE, B. "Ich war krank und ihr habt mich besucht" (Mt 25,36) [I]. Erbe und Auftrag, v. 40, p. 443458, 1964; STEIDLE, B. "Ich war krank und ihr habt mich besucht" (Mt 25,36) [II]. Erbe und Auftrag, v. 41, (p. 36-46,99-113,189-206), p. 197, 1965, pressupõe a existência de ascetas na Basilíada. Ele até os equipara aos guardas e médicos.

${ }^{10}$ Sob esse termo devem-se entender os chamados paralabani. Segundo PHILIPSBORN, Alexander. Der Fortschritt in der Entwicklung des byzantinischen Krankenhauswesens. Byzantinische Zeitschrift, v. 54, p. 338-365, 1961, p. 363, eles tinham primordialmente a tarefa de procurar doentes nas ruas e estradas, levá-los para hospitais ou instituições diaconais e lavá-los; cf. também VOLK, 1983, p. 41, especialmente nota 16.

${ }^{11}$ Basílio não tinha uma atitude inteiramente positiva para com os médicos, pois eles só seriam responsáveis por uma parte das enfermidades. Doenças também poderiam ser consequência e punição para o pecado, e neste caso elas não deveriam ser tratadas por médicos; cf. STEIDLE, 1965, II, p. 110. Em consonância 
disso, havia funcionários para a organização prática. A Basilíada não constituía apenas um hospital, uma hospedaria e um monastério. É preciso também imaginar a existência de instalações para o dia a dia, banheiros e oficinas ${ }^{12}$ no terreno ocupado por ela. ${ }^{13}$ Basílio, que mais tarde se tornaria bispo, via nisso uma contribuição para reconstruir a região que sofria com problemas econômicos e colonização insuficiente. ${ }^{14}$ De qualquer modo, em sua época, o próprio muro da cidade de Cesareia já estava ruindo. Portanto a Basilíada era, ao mesmo tempo, um grande empreendimento econômico que beneficiava a região e um centro espiritual.

Em outras de suas cartas, Basílio designou o empreendimento como uma instituição para os pobres (ptochotrophê̂on) diante da cidade. ${ }^{15}$ Ele próprio podia ser encontrado nela regularmente. Convidou hóspedes oficiais como o bispo Anfilóquio de Icônio, no marco da visita deste para a Festa dos Mártires (Festa de Eupsíquio) em Cesareia, também para ficar na hospedaria para os pobres. ${ }^{16}$

Outras informações sobre a Basilíada são dadas por Gregório de Nazianzo em seu discurso memorial para Basílio. ${ }^{17}$ Em termos de história institucional, pode-se depreender das palavras de Gregório que seu amigo organizou, de fato, uma "nova cidade" diante dos portões de Cesareia. ${ }^{18}$ Essa designação indica que o complexo tinha dimensões consideráveis. Gregório via nela um engajamento tríplice: em favor da "filantropia", dos pobres (ptochotrophía) ${ }^{19}$ e dos doentes (boéthema anthropínes asteneîas), inclusive para os doentes de lepra. "Filantropia" poderia se referir à hospedagem de viajantes mencionada por Basílio. Segundo Gregório, Basílio também

com isso, ele também de modo algum previa para seus coirmãos, no caso de doença, simplesmente um tratamento médico no xenodochê̂on; cf. Bas., Regulae brevius tractatae 286 (PG 31, 1284B Migne).

12 Monges também atuavam nessas instalações; cf. Regulae fusius tractatae 38.41. Quanto aos monges nas oficinas, cf. também Bas., Regulae brevius tractatae 141 (1177 M.).

13 O que Basílio chama de "instalações para o modo de vida refinado" decerto deve ser interpretado como banheiros, que em todo caso faziam parte de instituições para o acolhimento de pessoas doentes (cf. abaixo).

14 Da ep. 94, em todo caso, não se podem depreender mais informações sobre a motivação de Basílio. VISCHER, Lukas. Basilius der Große: Untersuchungen zu einem Kirchenvater des vierten Jahrhunderts. Basel, 1953. p. 141, não indica fontes para suas observações: "As pessoas doentes da cidade não encontravam cuidados em lugar algum, e quando forasteiros passavam por Cesareia em viagem não havia um alojamento à disposição deles. Por isso Basílio elaborou o plano de erigir uma série de prédios para enfermos e estrangeiros".

${ }^{15}$ Cf. Bas., ep. 150,3 (CUFr, Bd. 2, 74,3 Courtonne). Em ep. 150,3 se encontra também um estímulo mais longo de Basílio para a partilha segundo Lc 3.11; Mt 10.10; 13.46; 19.21. Basílio também acentuava que se deveria deixar a administração dos bens dos pobres por conta de pessoas com essa atribuição específica. Elas teriam melhores condições de identificar os verdadeiramente carentes.

${ }^{16}$ Cf. Bas., ep. 176 (CUFr, v. 2, 113,19-21 C.).

17 Gr. Naz., or. 43,63 (SC 384, 260-264 Bernardi). Gregório redigiu sua or. 43 cerca de dois anos após o falecimento de seu amigo e decerto procurou, por meio dela, fortalecer sua própria posição, além de traçar seu ideal do modo de vida cristão. Ainda assim, no discurso devem se encontrar informações historicamente confiáveis.

${ }^{18}$ CRISLIP, 2005, p. 104, acentua que a localização de uma grande instituição caritativa diante dos portões da cidade seria um fenômeno inteiramente novo, pois até então as pousadas e os sopões da igreja se encontravam dentro das próprias cidades.

19 CRISLIP, 2005, p. 107, indica que o termo ptochós de modo algum se refere a membros da classe social inferior (pénes), e sim às pessoas inteiramente desprovidas de recursos e lar. 
se dedicava pessoalmente aos doentes de lepra, que, em regra, foram excluídos da sociedade da Antiguidade. ${ }^{20}$

Segundo Gregório, a instituição era financiada, ao menos em ocasiões pontuais, pelas pessoas responsáveis pela sociedade. Basílio conseguiu persuadi-las de que a atividade diaconal e caritativa era uma tarefa comum a todos. ${ }^{21}$ Informações sobre o financiamento da instituição também se encontram em outras fontes: a Historia ecclesiastica de Teodoreto de Ciro, escrita após 428 - que, porém, caracteriza-se por elementos legendários -, menciona um apoio da assistência prestada por Basílio aos pobres e doentes por parte do imperador Valêncio (364-378). Para essa finalidade, o imperador teria doado a Basílio as melhores terras existentes no entorno. ${ }^{22}$ Em sua correspondência, Basílio solicitou, com vistas a outros projetos em favor dos pobres, apoio estatal e isenção fiscal. ${ }^{23} \mathrm{E}$ de se supor que ela tenha apresentado requerimentos semelhantes para sua Basilíada.

Repassemos agora ainda as demais fontes referentes à instituição. Gregório de Nissa acentuou, em um discurso sobre seu irmão Basílio, o caráter espiritual das instalações localizadas nos arrabaldes da cidade (proásteion) ${ }^{24}$.

Esse grande empreendimento diaconal também ainda era perfeitamente conhecido no século V. ${ }^{25}$ Um dos sucessores de Basílio, chamado Firmo de Cesareia (m. em 439), falou sobre o assunto em carta dirigida a um alto funcionário (Inachios). Nessa carta, escrita antes do ano de 439, registra-se pela primeira vez o nome da instituição: Firmo falou da "Basilíada". Alguns pobres, a saber, escravos domésticos fugitivos, teriam encontrado asilo temporário nela. ${ }^{26}$ Também o historiador da igreja Sozomeno mencionou a instituição em sua Historia ecclesiastica redigida por volta de 450 d.C. A importante casa para abrigar os pobres (episemótaton katagógion ptochôn) teria sido chamada, desde o início, pelo nome de seu fundador. Seu dirigente seria um monge chamado Prapidios, que, ao mesmo tempo, atenderia muitas aldeias na função de

${ }^{20}$ Gregório de Nazianzo salientou que só as pessoas mais piedosas ainda mantinham contato com leprosos (Gr. Naz., or. 14,11 [PG 35, 872A Migne]), mas que, não obstante, eles deveriam receber assistência abnegada (Gr. Naz., or. 8.14 [PG 35, 868A-B; 876A Migne]).

${ }^{21}$ Cf. ainda Gr. Presb., de Gr. Naz. 11 (CChr.SG 44, 156-158 Lequeux), segundo o qual Basílio teria inclusive fixado taxas anuais (prosódous etesías táxas) para o apoio da instituição por parte dos ricos. Apoios por parte de ricos também estão documentados em outras passagens de Gregório de Nazianzo (cf. Gr. Naz., ep. 211 a Ciríaco [PG 37, 348C Migne]), onde, entre outras coisas, fala-se dos fazendeiros Liriando, Ceberinas e Castor. Ciríaco deveria isentar essas áreas de tributação para assegurar a assistência aos pobres.

22 Cf. Teodoreto, h.e. IV 19,13 (GCS Theodoret, 245,12-15 Parmentier/Hansen). Quanto ao financiamento do grande projeto, cf. também KOSCHORKE, 1991, p. 309s.

${ }^{23}$ Cf. Bas., ep. 142 a um numerarius do prefeito, isto é, um contabilista do praefectus praetorio em Constantinopla (CUFr, v. 1, 65,10-12 C.). Basílio também pressupôs o auxílio estatal no caso da instituição para os pobres (ptochotrophê̂on) em Amásia (Bas., ep. 143 [CUFr, v. 2, 65,11s C.]). Por fim, em ep. 144 (CUFr, v. 2, 66,6s C.) Basílio também fala em apoio aos pobres por parte de um funcionário do prefeito.

24 Gr. Nyss., In Basilium fratrem (GNO X/1, 127, 20 Lendle).

25 É possível que também a afirmação de João Crisóstomo de que teria procurado em vão possibilidades de tratamento para sua doença na Isáuria, mas as teria encontrado em Cesareia seja interpretada como uma referência à Basilíada; cf. Chrys., Epistula ad Olympiadem 4 (SC 13bis, 116-118 Malingrey).

${ }^{26}$ Cf. Firm., ep. 43 (SC 350, 166 Calvet/Gatier). 
bispo (rural). ${ }^{27}$ Portanto, segundo as fontes do século V, a Basilíada exercia um papel central especialmente para a assistência aos pobres. Não há mais referências explícitas posteriores ao complexo.

Não se conhecem resquícios arqueológicos da Basilíada. ${ }^{28}$ Isso tem a ver com as destruições ocorridas no século XI, entre outros, e com as construções modernas erguidas sobre o terreno. Possivelmente a basílica, da qual ainda existem registros fotográficos, demolida em 1965, era um último testemunho da magnitude da Basilíada: com um comprimento de ao menos $60 \mathrm{~m}$ e uma largura de ao menos $30 \mathrm{~m}$, ela era, em todo caso, considerada uma das construções de grande porte da Ásia Menor. ${ }^{29}$

Digna de nota, porém, não era tanto a dimensão da Basilíada, e sim a combinação inovadora de hospedaria para estrangeiros, casa para os pobres e hospital em uma instituição pública, que, por sua vez, estavam associados a uma espécie de vida conventual. ${ }^{30} \mathrm{Na}$ pesquisa se usou o termo "instituição mista" para designá-la. ${ }^{31}$ No que segue se irá perguntar se na Antiguidade e na Antiguidade tardia houve modelos institucionais para essa instalação mista.

\section{Modelos históricos}

A pesquisa pregressa salientou especialmente uma derivação histórica intracristã do grande projeto de Basílio. ${ }^{32}$ Tal modelo estaria dado pela hospedaria para estrangeiros fundada pelo mestre paternal de Basílio e seu amigo Eustácio em Sebastia, que hoje se chama Sivas ${ }^{33}$, situada a cerca de $190 \mathrm{~km}$ de distância de Cesareia.

27 Cf. Soz., h.e. VI 34,9 (GCS Sozomenus, 291 Bidez/Hansen). Segundo a afirmação de Sozomeno de que Prapidios pollàs epeskópei komas, este último deve ter sido corepíscopo.

${ }^{28}$ Cf. as observações sintéticas em HILD, Friedrich; RESTLE, Marcell (Orgs.). Kappadokien (Kappadokia, Charsianon, Sebasteia und Lykandos). Wien: Verlag der Österreichischen Akademie der Wissenschaften, 1981. p. 193-195.

29 Quanto à basílica de Cesareia identificada arqueologicamente, mas destruída em 1965 quando da construção de uma estrada, cf. RESTLE, Marcell. Studien zur frühbyzantinischen Architektur Kappadokiens: v. 1. Text. Wien: Verlag der Österreichischen Akademie der Wissenschaften, 1979. p. 44s.

${ }^{30}$ Cf. GIET, 1941, p. 422: “O que é próprio a São Basilio - o que surpreendeu seus contemporâneos - é a ideia destes serviços múltiplos, suas organizações, a amplitude que lhes dá.“ Tradução do editor. "Ce qui est propre à saint Basile - ce qui a supris ses contemporains -, c'est l'idée de ces multiples services, leur organisations, l'ampleur qu'il leur donne."

${ }^{31}$ Cf., entre outros, KISLINGER, Ewald. Hospital, II. Byzantinisches Reich. In: Lexikon des Mittelalters. München, 1991. v. 5, (p. 133s) p. 133.

32 CRISLIP, 2005, p. 120-133, dedica-se extensamente à derivação histórica da Basilíada. Neste contexto, ele discute a possível derivação de santuários de Asclépio, clínicas médicas privadas, médicos públicos, enfermarias para escravos e militares (valetudinários) e, por fim, instituições no entorno de cristãos "arianos" como Eustácio e também Maratônio de Constantinopla ou Nicomédia. Estes últimos poderiam ter ao menos estimulado Basílio a desenvolver uma instituição análoga. Crislip rejeita, com boas razões em cada caso, uma derivação direta da Basilíada de todas essas instituições. Ele supõe, isto sim, que o monaquismo seja o pano de fundo direto da instituição situada diante dos portões de Cesareia.

${ }^{33}$ Cf. HILTBRUNNER, Otto. Krankenhaus. In: Reallexikon für Antike und Christentum. Stuttgart: Hiersemann, 2006. v. 21, col. 882-914, col. 900. Os ptocheîa que Macedônio teria criado já sob Constâncio II até agora praticamente não receberam atenção; cf. Soz., h.e. IV 20,2 170 B./H. 
Antes de nos voltarmos para esse modelo em potencial, mencionaremos também um possível modelo do entorno dos esforços pagãos de restauração: os xenodocheîa do imperador Juliano.

\section{Os xenodocheîa do imperador Juliano}

Em sua conhecida Epistula 84 do ano de 362 d.C., o imperador Juliano conclamou Arsácio, sumo sacerdote da Galácia, a mandar erguer hospedarias para estrangeiros (xenodocheîa) em todas as cidades, para que os estrangeiros pudessem desfrutar da filantropia pagã. ${ }^{34}$ Juliano, que como imperador romano tinha buscado pela última vez a restauração do paganismo, procurou, com isso, contrapor uma ênfase clara à prática cristã do amor ao próximo. Ciente da eficiência propagandística da atividade diaconal e caritativa cristã, principalmente da hospedagem de forasteiros e do sepultamento de mortos, o imperador não só conclamou os sacerdotes da Galácia a adotar uma prática semelhante, mas também concedeu, ele mesmo, 30 mil alqueires de cereais e 60 mil medidas de vinho para toda a Galácia em favor dos pobres a serviço dos sacerdotes, dos estrangeiros e dos mendigos. Além disso, as diversas comunidades deveriam contribuir para apoiá-los em âmbito local, "pois" - assim fundamenta o imperador sua exigência - "seria uma vergonha que entre os judeus nenhum deles precisa mendigar, que os gálatas ímpios (isto é, os cristãos) ainda deem de comer aos nossos mendigos além dos deles, que nossa própria gente fique sem qualquer apoio de nossa parte diante dos olhos de todos" ${ }^{35}$. Ocasionalmente se viu no programa do imperador Juliano o modelo para o grande projeto diaconal e caritativo de Basílio. ${ }^{36}$ Ele teria ao menos servido de estímulo para contrapor algo à atividade caritativa pagã. Pode-se observar uma confrontação intensiva com o imperador apóstata particularmente no caso de Gregório de Nazianzo, que, entretanto, via na criação de instituições caritativas e até semimonásticas apenas uma espécie de trapaça por parte do imperador, que, de qualquer modo, teria macaqueado seus projetos dos cristãos. ${ }^{37}$ Certamente houve esse tipo de situação de concorrência entre a assistência pagã e a cristã. Puramente do ponto de vista da história das instituições, porém, o projeto do imperador dificilmente pode ser comparado ao de Basílio. O interesse primordial do imperador era a hospedagem de forasteiros e o simultâneo apoio a pessoas carentes. No caso dele não há menção de um cuidado dos doentes ${ }^{38}$ e tampouco de uma conexão direta entre a hospedagem de

${ }^{34}$ Quanto ao projeto do imperador Juliano, cf. recentemente KISLINGER, Ewald. Kaiser Julian und die (christlichen) xenodocheia. In: HÖRANDNER, Wolfram et al. (Orgs.). Byzantios: Festschrift für Herbert Hunger zum 70. Geburtstag. Wien: Becvar, 1984. p. 171-184.

35 Juln. Imp., ep. 84 (CUFr, v. I/2, 145,17-20 Bidez).

${ }^{36}$ Cf. UHLHORN, Gerhard; HAUCK, Albert. Wohltätigkeitsanstalten. In: Realenzyclopädie für protestantische Theologie und Kirche. 3. ed. Leipzig: Hinrichs, 1908. v. 21, p. 435-452, p. 437.

37 Cf. Gr. Naz., or. 4,111 (PG 35, 648C Migne). Já Gregório acentuava que Juliano teria recebido dos cristãos os estímulos para suas instituições caritativas. Em or. 4,112 ele até fala de "macaqueação".

${ }^{38}$ KISLINGER, 1984, p. 177, fala, por causa da concepção particular do imperador, de uma modificação restritiva da concepção cristã dos xenodecheîa por parte de Juliano. 
estrangeiros e o culto religioso. Por isso, do ponto de vista da história das instituições, o modelo para a Basilíada deve ser buscado alhures.

\section{A hospedaria para forasteiros em Sebastia}

A hospedaria para forasteiros em Sebastia fora erigida primordialmente para monges itinerantes, mas também para peregrinos e pobres. ${ }^{39}$ Estamos informados sobre essa hospedaria principalmente por meio do "Espelho de hereges" de Epifânio de Salamina, o chamado Panarion (374-377) ${ }^{40}$. Após sua entronização no cargo de bispo em 355 d.C., Eustácio tinha passado para seu ex-colega de ascese Aério (n. por volta de 300 ; m. depois de 375$)^{41}$ a direção de uma hospedaria para forasteiros (xenodocheîon). Na região, ela era designada como hospedaria para pobres (ptochotropheîon). No marco da hospitalidade, pessoas feridas e inválidas também foram alojadas lá. A hospedaria foi apoiada pelos dirigentes das comunidades, sendo, portanto, mantida pela igreja. Aério já deixou a hospedaria após pouco tempo, provavelmente por volta de 360 d. C., por causa de conflitos com Eustácio.

Wolf-Dieter Hauschild sustenta, com razão, que Basílio conhecia a hospedaria. De Epifânio, contudo, não se podem depreender informações precisas sobre a estrutura dela. ${ }^{42}$ Faltam, principalmente, referências a uma espécie de infraestrutura clerical ou até conventual, com igreja e alas com celas, que estivessem ligadas à hospedaria para forasteiros, pobres e doentes. Não é certo que em Sebastia realmente houvesse uma instituição mista com um hospital de verdade..$^{43}$ Em especial, para poder explicar historicamente essa combinação característica da Basilíada, deve-se dirigir o olhar ainda para além da Ásia Menor, para uma região da qual tanto Basílio como Eustácio receberam impulsos: o Egito.

\section{Os monastérios pacomianos}

No Egito existiam, desde os anos 20 do século IV, instituições de grande porte em que se encontravam, em um complexo, instalações para doentes, estrangeiros e

39 Cf. BASILIUS, 1990, p. 219s, nota 412. KISLINGER, 1984, p. 175, vê a tarefa do xenodochê̂on primordialmente no atendimento de pessoas destituídas de recursos, mas também no cuidado dos doentes.

40 Cf. Epiph., haer. 75 (GCS Epiphanius III, 333,22-27 Holl/Dummer).

${ }^{41}$ Quanto a Aério, cf. MEYER, Philipp. Aërius. In: Realenzyclopädie für protestantische Theologie und Kirche. 3. ed. Leipzig: Hinrichs, 1896. v. 1, p. 232s.

42 Epifânio também nada diz sobre a época da fundação da instituição em Sebastia e a origem do conceito de hospedaria. Poder-se-ia pensar até na prática de hospedar peregrinos existente no judaísmo. Provavelmente antes de 70 d. C. já houve em Jerusalém, em uma sinagoga construída por Teodoto, filho de Veteno, uma hospedaria (xenón), em que se mencionam explicitamente uma despensa e uma instalação com água (para os banhos rituais?); cf. a inscrição de Teodoto (CIJ 1401) reproduzida e transliterada em KÜCHLER, Max. Jerusalem: Ein Handbuch und Studienreiseführer zur Heiligen Stadt. Göttingen: Vandenhoeck \& Ruprecht, 2007. p. 79s.

${ }^{43}$ CRISLIP, 2005, p. 129, pressupõe, p. ex., que em Sebastia não teria existido um atendimento médico real. 
pessoas sem posses. Trata-se dos conventos pacomianos, em que, segundo Paládio, sete mil monges, entre outros, teriam vivido no início do século V. ${ }^{44}$

Podem-se encontrar numerosos vestígios de engajamento diaconal e caritativo não só na Vita do abade fundador Pacômio ${ }^{45}$, mas também nas regras do monastério. ${ }^{46}$ $\mathrm{Na}$ primeira e mais antiga parte do conjunto de regras de Pacômio, nos chamados Praecepta $^{47}$, especialmente os preceitos 40 a 47 tratam do serviço aos pobres. Aí se mencionam ministros dos pobres (Praecepta 40), uma seção própria para os doentes (locus aegrotantium) e um refeitório ligado a ela (triclinum aegrotantium; Praecepta 42). ${ }^{48}$ A seção dos doentes, onde só deveriam ficar pacientes, era separada do convento. ${ }^{49}$ Os doentes só podiam ser visitados e cuidados por coirmãos com permissão dos anciãos do monastério. ${ }^{50}$ Ao que parece, na seção de doentes do convento eram tratados exclusivamente monges. ${ }^{51}$ Nos escritos pacomianos não se menciona a presença de médicos dentro dos monastérios. ${ }^{52}$ Em compensação, também neste caso se deve supor que houvesse a possibilidade de tomar banho nas proximidades da seção dos enfermos. ${ }^{53}$

44 Pall., h. Laus. 32 (TaS 6/2, 93,8 Butler). Uma posição crítica quanto a isso se encontra em GROSSMANN, Peter. Christliche Architektur in Ägypten. Leiden: Brill, 2002. p. 252. Ele supõe, com base em Epistula Ammonis 2 e 21, que houvesse um total de dois mil monges (em Epistula Ammonis 2 [SH 19, 98,4 Halkin] se fala de 600 monges em Pbow, em Epistula Ammonis 21 de mais de dois mil monges presentes no capítulo geral [SH 19, 110,18f. H.]).

${ }^{45}$ Cf. Vita Pachomii graeca prima 28 (SH 19, 17s Halkin).

46 Já em Jerônimo, reg. Pachom. praef. 5 (traduzido em BACHT, Heinrich. Das Vermächtnis des Ursprungs. Studien zum frühen Mönchtum. Würzburg: Echter, 1983. v. 2: Pachomius - der Mann und sein Werk, p. 67 - introdução à tradução de todos os textos de Pacômio para o latim do ano de 404), o pai da igreja menciona que nos monastérios pacomianos as pessoas doentes eram tratadas generosamente.

47 As citações dos Praecepta são feitas segundo BACHT, 1983, p. 82-114. Na exposição, limito-me à tradução do conjunto de regras feita por Jerônimo.

48 VOLK, 1983, p. 34, nota 46, sublinha que na tradução latina de Jerônimo o termo valetudinarium não é empregado para designar os hospitais nos monastérios pacomianos. Também nos excertos gregos não se encontram termos comparáveis a esse. Do ponto de vista da história das instituições, porém, não se deveriam tirar disso conclusões de muito peso. Uma instituição semelhante não necessita automaticamente de um termo semelhante.

49 Não há nada que deponha a favor da ideia de que os doentes morassem em suas celas habituais e só fossem atendidos na seção dos enfermos. Nas Vitae saídicas de Pacômio existem, em todo caso, comprovantes inequívocos para uma espécie de enfermaria comum. Assim, na Vita Pachomii sahidice scripta decima (CSCO, 2. ed., 99/100 = CSCO.C, 2. ed., 9/10, 35 Lefort) se diz que os irmãos enfermos fazem as refeições juntos em um lugar. Um irmão jovem também é levado e alimentado nesse local. A Vita Pachomii sahidice scripta tertia (CSCO, 2. ed., 99/100 = CSCO.C, 2. ed., 9/10, 75s Lefort) relata que o próprio Pacômio, doente de febre, foi levado ao lugar em que todos os irmãos doentes se encontravam. Lá ocorreu um conflito entre ele e Teodoro porque este último queria cobri-lo com uma coberta melhor do que aquela que cabia aos outros irmãos.

${ }^{50}$ Dentro da seção dos doentes parece ter havido uma espécie de despensa que é designada como cella aegrotantium ou cella languentium (Praecepta 53s). Por fim, nos Praecepta atque iudicia 5 (STGL 8, 257 Bacht) também se fala de um locus infirmorum (cf. de maneira semelhante também Praecepta atque iudica 12 [259 B.]). GROSSMANN, 2002, p. 300, interpreta esse local como um leprosário.

${ }^{51}$ Cf. GROSSMANN, 2002, p. 255.

52 Cf. também GROSSMANN, 2002, p. 300. De modo geral, no monaquismo egípcio havia médicos o mais tardar na época de Paládio, p. ex. na Nítria; cf. CRISLIP, 2005, p. 14.

${ }^{53}$ Cf., entre outros, GROSSMANN, 2002, p. 301. 
Também hóspedes passageiros ${ }^{54}$ eram acolhidos nas instalações dos conventos pacomianos. ${ }^{55}$ Provavelmente eles eram alojados gratuitamente em uma pousada própria, decerto separada, fora do monastério (Praecepta 50).${ }^{56}$ A pousada era chamada de xenodochium. Nela, os hóspedes também eram alimentados. No xenodochium eram alojados especialmente clérigos e outros monges. Só eles podiam participar da oração dos monges do próprio monastério. ${ }^{57}$ Também mulheres (designadas como vasa infirmiora), pessoas seculares (saeculares homines) e mendigos (debiles) eram hospedados in diversis locis no convento ou na frente dele. As mulheres deveriam ser alojadas em recintos separados e trancados, "para que não surja ocasião de suspeita" (Praecepta 52).$^{58}$ Por conseguinte, pessoas pobres também encontravam alojamento e apoio nos monastérios, sendo, além disso, igualmente alimentados. ${ }^{59}$

Em termos de história das instituições, a organização dos conventos pacomianos deve ter se baseado em modelos. Não é possível fazer afirmações definitivas sobre isso, entre outras razões porque os monastérios praticamente não foram pesquisados arqueologicamente. ${ }^{60}$ Provavelmente se devem procurar modelos em especial para as enfermarias no âmbito da arquitetura militar. ${ }^{61}$

\section{Acampamentos militares romanos}

As descrições que se encontram na literatura pacomiana levaram Derwas Chitty a supor, já em 1966, que o plano de conjunto dos monastérios pacomianos se orientasse por acampamentos militares. O que depõe a favor disso é o fato de que o

${ }^{54}$ GROSSMANN, 2002, p. 295, distingue dos hóspedes passageiros aqueles que pretendiam entrar no monastério e, para isso, precisavam primeiro morar cerca de uma semana fora do convento em uma pousada própria (cf. Praecepta 49). Entretanto, não há uma referência inequívoca a uma pousada à parte, e sim só a uma estada fora do monastério; cf. o texto da edição de Bacht (92 B.): et manebit paucis diebus foris ante ianuam.

${ }^{55}$ GROSSMANN, 2002, p. 255, acentua inclusive que um xenodocheîon em todo caso fazia parte de um monastério cenobita. A arqueologia não comprova a existência de pousadas; cf. GROSSMANN, 2002, p. 297.

56 GROSSMANN, 2002, p. 296, fala de um alojamento no "interior" do convento, mas não apresenta abonações para isso. Segundo Vita Pachomii graeca prima 40 (24 H.), Pacômio não deixava nem mesmo monges vindos de outros lugares entrarem no interior do monastério, mas os alojava en tópo tini kat'idian pròs taîs thýrais.

57 Neste sentido, Praecepta 51 pressupõe a fé correta. Isso, por sua vez, significa que, em princípio, essa fé não era necessária para o alojamento de hóspedes.

${ }^{58}$ Quando mulheres chegavam ao monastério à noite, elas não podiam mais, de modo algum, ser mandadas embora.

${ }^{59}$ Cf. particularmente Paralipomena 35 (SH 19, 160,20s Halkin), onde se fala da alimentação de pobres e forasteiros.

${ }^{60}$ Cf. KRAUSE, Martin. Das Mönchtum in Ägypten. In: (Org.). Ägypten in spätantik-christlicher Zeit: Einführung in die koptische Kultur. Wiesbaden: Reichert, 1998. p. 149-174, p. 157.

${ }^{61}$ CRISLIP, 2005, p. 126s, não refletiu sobre esses possíveis precursores, mas viu, mesmo assim, nos valetudinários dos acampamentos militares também os mais próximos paralelos extracristãos aos xenodocheîa $\mathrm{e}$ nosokomeîa cristãos. Neste contexto, ele acentuou que não se deve supor que tenha havido uma influência direta do "hospital cristão" por parte da estrutura dos acampamentos militares, mas não refletiu sobre o desvio pelos pacomianos. 
próprio Pacômio foi soldado ${ }^{62} \mathrm{e}$, na organização de monastérios, podia facilmente, com várias centenas de monges, recorrer a formas organizacionais dos militares. ${ }^{63}$ Também a divisão dos conventos dos pacomianos em diversas casas ou prédios com 20 a 40 monges lembra as barracas que se encontram em acampamentos militares romanos. Embora estes últimos só possam ser designados de modo muito restrito como "instituição mista", podem-se, ao menos, observar analogias parciais com os complexos conventuais. Junto com Peter Grossmann, que pode ser considerado o melhor conhecedor dos resquícios arqueológicos cristãos no Egito, pode-se ver esse tipo de analogia a partir do exemplo das enfermarias em monastérios e em acampamentos militares. ${ }^{64}$ Nestes últimos, as enfermarias eram chamadas de "valetudinários".

Os valetudinários são tidos como as únicas instituições da Antiguidade destinadas a um tratamento mais prolongado, puramente médico e não ambulatorial de pessoas doentes. ${ }^{65}$ Tais "enfermarias" já existiam desde o final do século I a.C. em propriedades rurais e grandes domicílios urbanos, entre outros locais. ${ }^{66}$ Elas serviam para o tratamento de escravos ou serviçais. ${ }^{67}$ Mas os valetudinários se encontravam principalmente em guarnições fixas dos romanos. ${ }^{68} \mathrm{Um}$ paradigma excelente disso é constituído pelo acampamento principal de Haltern, instalado por volta do ano 5 d.C. na extremidade meridional da atual região de Münster. Essas enfermarias existiam ao longo da circunvalação do acampamento na via principalis. Elas se destinavam exclusivamente ao tratamento de soldados adoentados ou feridos. Portanto os pacientes provinham - de modo análogo aos monastérios pacomianos - quase exclusivamente do acampamento. ${ }^{69}$ As enfermarias estavam, na maioria dos casos, localizadas em torno de um pátio interno quadrado. No valetudinarium em Neuss, entre outros locais,

${ }^{62}$ Cf. ROUSSEAU, Philip. Pachomius: The Making of a Community in Fourth-Century Egypt. Berkeley: University of California, 1985. p. 58, ou Vita Pachomii graeca prima 4 (3,15s H.); Vitae Pachomii bohairice scriptae $7 \mathrm{~s}$ (81-83 L.).

${ }^{63}$ Cf. CHITTY, Derwas J. The Desert a City: An Introduction to the Study of Egyptian and Palestinian Monasticism under the Christian Empire. Oxford: Blackwell, 1966. p. 22.

${ }^{64}$ Cf. GROSSMANN, 2002, p. 299: "Não é certo, contudo, que neste caso se trate efetivamente de uma espécie de hospital (nosokomion) ou de um valetudinarium como os dos acampamentos militares".

${ }^{65}$ Quanto aos valetudinários, cf., entre outros, HARIG, G. Zum Problem "Krankenhaus" in der Antike. Klio, v. 53, p. 179-195, 1971, p. 188-194.

66 Também há registro da existência de valetudinários nas casernas de gladiadores.

${ }^{67}$ Cf., entre outros, Colum., De re rustica XI 1,18 (COLUMELLA. Zwölf Bücher über Landwirtschaft. Buch eines Unbekannten über Baumzüchtung, hg. und übersetzt von W. Richter. Darmstadt: Wissenschaftliche Buchgesellschaft, 1982. Bd. 3, p. 20, p. 149-152). Xenofonte critica o fato de que o atendimento médico de escravos visava meramente ao interesse próprio do escravagista na conservação da força de trabalho; cf. X., mem. II 4,3 (Sammlung Tusculum, 117 Jaerisch).

${ }^{68}$ Cf. Pseudo-Hyginus, De munitionibus castrorum 4 (CUFr, 3 Lenoir). Além disso, quanto aos valetudinários militares, cf. também VOLK, 1983, p. 6-8; PETRIKOVITS, Harald von. Die Innenbauten römischer Legionslager während der Prinzipatszeit. Opladen: Westdeutscher Verlag, 1975

69 WILMANNS, Juliane C. Der Sanitätsdienst im Römischen Reich: Eine sozialgeschichtliche Studie zum römischen Militärsanitätswesen nebst einer Prosopographie des Sanitätspersonals. Hildesheim: Olms-Weidmann, 1995. p. 134, não exclui um atendimento de civis, mas não apresenta abonações para sua afirmação. Provavelmente, pode-se supor tal atendimento nos valetudinários militares no máximo em situações de emergência. 
foram encontrados instrumentos cirúrgicos que poderiam indicar a existência de uma sala de operações. De maneira semelhante à Basilíada, nas enfermarias havia locais para banho. As instalações dispunham de enfermeiros próprios (valetudinarii) e médicos militares (medici castrenses) e são, também neste tocante, ao menos análogos ao complexo de Basílio. ${ }^{70}$

\section{Conexões do ponto de vista da história das instituições}

Pacômio poderia ter assumido no projeto de seus conventos o valetudinarium que conhecia a partir dos acampamentos militares. Em todo caso, ele não dispunha de outro modelo para o tratamento não ambulatorial de pessoas enfermas. ${ }^{71}$ Além disso, os monastérios dos pacomianos devem ser designados como uma espécie de instalação mista. Por esse seu caráter de instalação mista, eles se encontravam em grande proximidade com a Basilíada enquanto instituição. Basílio, entretanto, abriu - como provavelmente já acontecera antes em Sebastia - a enfermaria para pacientes de fora. Mas Basílio podia, afinal, orientar-se pelas instalações mistas existentes no Egito?

Segundo Wolf-Dieter Hauschild, Basílio não conhecia conventos pacomianos. ${ }^{72}$ Ainda assim, é de se supor que Basílio estivesse familiarizado com o monacato pacomiano. O que depõe em favor disso são as informações dadas por Gregório de Nazianzo em seu discurso memorial para Basílio, em que relata algo assim como viagens de formação pessoal em assuntos atinentes ao monacato que Basílio teria feito antes de iniciar sua carreira monacal e eclesiástica. ${ }^{73}$ Mais importantes ainda são as afirmações do próprio Basílio. ${ }^{74}$ Especialmente na Epistula 223, Basílio relatou a respeito de encontros que tivera com ascetas rigorosos em uma viagem feita após a conclusão de seus estudos. Ao fazer isso, ele chegou, entre outros locais, até Alexandria e também "ao restante do Egito". ${ }^{75}$ Quando procurou lá modelos de vida ascética, Basílio deve ter recebido informações sobre os pacomianos, mesmo que não tenha viajado até a Tebaida, no Alto Egito. ${ }^{76}$ Temos boas informações das fontes a respeito

${ }^{70}$ HARIG, 1971, p. 188, indica, entretanto, que possivelmente não havia médicos com formação científica nos valetudinaria.

71 WILMANNS, 1995, p. 136, considera concebível que os valetudinários militares tenham oferecido os modelos para o desenvolvimento do hospital cristão no século IV, mas não levou em consideração a possível intermediação por parte dos monastérios cenobitas.

72 Cf., entre outros, BASILIUS, 1990, p. 6s; p. 161, nota 2.

${ }^{73}$ Cf. Gr. Naz., or. 43,25 (182,9-11 B.).

${ }^{74}$ Em Bas., ep. 1 para Eustácio, Basílio mencionou sua viagem de Atenas, passando por Constantinopla e pela Ásia Menor, até a Síria e, por fim, inclusive até Alexandria. ROUSSEAU, 1994, p. 73, data essa viagem por volta de $356 / 357$.

75 Bas., ep. 223,2 (CUFr, v. 3, 10,20s Courtonne). Em ep. 223 (CUFr, v. 3, 10,13-15 C.), Basílio descreve sua opção pelo "caminho da perfeição" e a dedicação aos pobres igualmente associada a ela.

${ }^{76}$ Hauschild é de opinião que "o restante do Egito" se refere à província do Egito, mas que Basílio dificilmente chegou à Tebaida, no Alto Egito, até os pacomianos. Quanto à discussão sobre o conhecimento dos pacomianos por parte de Basílio, cf. ROUSSEAU, 1994, p. 73, nota 53. 
da mobilidade dos pacomianos, particularmente também na direção de Alexandria. ${ }^{77}$ Em 391, eles até instalaram um monastério no vale do Canopo, que ficava a apenas poucos quilômetros de distância de Alexandria. ${ }^{78}$ Mesmo que ele só tenha sido instalado após a visita de Basílio a Alexandria, a vida cenobita pacomiana ou análoga a ela deve ter sido conhecida na metrópole egípcia. ${ }^{79}$ Por que Basílio não haveria de ter assumido ao menos esse elemento do monaquismo pacomiano?

\section{Uma "maravilha do mundo" cristã}

Portanto, puramente do ponto de vista da história das instituições, Basílio não introduziu nada realmente novo. Para sua instalação mista ele pôde recorrer aos monastérios dos pacomianos. O que, ainda assim, induziu Gregório de Nazianzo a comparar esse empreendimento à primeira vista de modo algum emocionante às famosas "maravilhas do mundo" da Antiguidade? A maravilha encontrava-se menos em uma arquitetura de destaque ou realização artística, e sim, antes, em um nível que deve se delinear teologicamente.

Para Basílio, uma vida cristã segundo o evangelho ou segundo o exemplo da protocomunidade e no discipulado de Cristo tinha importância central. ${ }^{80}$ Também seu projeto diaconal e caritativo visava a uma realização coerente da vita evangélica ${ }^{81} \mathrm{~A}$ implementação de Mateus 25.35-40 ${ }^{82}$ certamente fomentou a cumulação de diversas instituições caritativas na Basilíada. Por conseguinte, deparamo-nos com Cristo não só no pobre, mas também no forasteiro e no doente. ${ }^{83}$ Uma organização mista com a qual

77 Cf., entre outros, Vita Pachomii sahidice scripta quinta 124.132 (271; 278 Lefort), Vita Pachomii graeca prima 113 (73s H.; sobre a circulação de mercadorias com Alexandria) e, resumindo, GOEHRING, James E. Withdrawing from the Desert: Pachomius and the Development of Village Monasticism in Upper Egypt. Harvard Theological Review, v. 89, p. 267-285, 1996, p. 274.

${ }^{78}$ Quanto ao Monastério de Metanoia no vale do Canopo, cf. a primeira menção em Jerônimo, reg. Pachom. praef. 1 (65 B.). Jerônimo recebeu de lá os escritos dos pacomianos por ele traduzidos e os traduziu para os monges que não dominavam egípcio e grego.

79 CRISLIP, 2005, p. 100, fala em termos mais gerais do monacato como modelo para a Basilíada.

${ }^{80}$ Quanto a isso, cf. de modo geral KOSCHORKE, 1991, p. 325-334. A ideia do discipulado também aparece explicitamente em Gr. Naz., or. 43,63 (SC 384, 264 B.): Basileíou dè hoi nosoûntes kaì tà tôn traumáton áke kaì he Christoû mímesis, où logo mén, ergo dè lépron kathaírontos ("[...] Basílio atribui muita importância aos doentes e à cura das feridas e ao discipulado de Cristo, purificando a lepra não com a palavra, mas com a ação").

${ }^{81}$ SCHNEEMELCHER, Wilhelm. Der Diakonische Dienst in der Alten Kirche. In: KRIMM, Herbert (Org.). Das Diakonische Amt der Kirche. 2. ed. Stuttgart: Evangelisches Verlagswerk, 1965. p. 61-103, p. 91, viu na implementação dos mandamentos do evangelho também na época da "igreja imperial" uma característica decisiva da diaconia.

82 Basílio exigiu a implementação de Mt 25.35-40, entre outras nas chamadas Regulae fusius tractatae 7 (PG 31, 928B-933C Migne); cf. ainda Bas., Regulae brevius tractatae 207 (1220C-D M.); quando à recepção de Mt 25.35 na igreja antiga, cf. especialmente PUZICHA, Michaela. Christus peregrinus: Die Fremdenaufnahme (Mt 25,35) als Werk der privaten Wohltätigkeit im Urteil der Alten Kirche. Münster: Aschendorff, 1980.

83 Neste sentido também deve ser entendida a afirmação contida em Gr. Naz., or. 14,27 (PG 35, 892D-893A Migne): Oudèn gàr hoútos, hos tò ê̂ poieîn, ánthropos échei theoû ("O ser humano não tem mais parte em Deus por meio de outra coisa do que fazer o bem”). Gregório, porém, pressupõe igualmente que devemos 
Basílio pôde tomar conhecimento por intermédio dos pacomianos oferecia a possibilidade de se encontrar com Cristo ao mesmo tempo em todo pobre, forasteiro e doente. ${ }^{84}$

As instituições assistenciais dos pacomianos estavam vinculadas à vida monástica. Para Basílio, o ideal da vida no monastério bem como da vida no mundo consistia na vita evangélica. ${ }^{85}$ Para ele, não havia uma distinção rigorosa entre convento e mundo. Justamente por isso podia transferir o modelo institucional dos monastérios pacomianos para o mundo, ao menos para a periferia de uma cidade. Devia-se buscar uma vida coerente com o evangelho no mundo, em toda a esfera pública, assim como no monastério. Com isso, o que temos em Basílio é mais do que simplesmente uma "incorporação do monaquismo" 86 em estruturas eclesiásticas.

É possível que tenha sido justamente essa abertura de estruturas conventuais para o mundo ${ }^{87}$, a necessária mistura de ideal ascético, fundamentado biblicamente de modo explícito por Basílio e uma instituição de grande porte próxima do mundo, que constituía a particularidade desse empreendimento e, com isso, desencadeou, ao mesmo tempo, contestação, que se refletiu na já mencionada carta de Basílio ao governador Elias. ${ }^{88}$ Basílio se defendeu dessas acusações apontando especialmente para a utilidade de seu empreendimento para o público.

Na pesquisa existe quase unanimidade na opinião de que a mistura de aspectos seculares e religiosos constituía o problema central para os adversários de Basílio. ${ }^{89}$ Uwe Walter Knorr divisou esses adversários na classe alta pagã de Cesareia, que teria acusado Basílio de, com suas ações sociopolíticas, imiscuir-se em assuntos do Estado. ${ }^{90}$ A oposição do lado pagão face à situação de acentuada concorrência entre o paganismo e o cristianismo é perfeitamente concebível. É duvidoso, porém, que a aristocracia urbana pagã tenha argumentado nesses termos com um governador obviamente cristão.

A contestação deve ter vindo, antes, do próprio cristianismo. Klaus Koschorke sugeriu que se buscasse a crítica a uma mistura de aspectos seculares e religiosos entre

nos encontrar com a outra pessoa como Deus; cf. Gr. Naz., or. 14,27 (896A M.: Soì egkataléleiptai ho ptochòs, hos theô [“O pobre te é confiado como Deus”]); PUZICHA,1980, p. 56. O encontro com Cristo se torna particularmente claro em Gr. Naz., or. 14,40 (909B-C M.).

${ }^{84}$ Certamente é insuficiente a observação de SAVRAMIS, Demosthenes. Zur Soziologie des byzantinischen Mönchtums. Leiden; Köln: Brill, 1962. p. 29, que vê na "hospitalidade" a ideia que se encontraria por trás dos xenodocheîa no pensamento de Basílio, entre outros.

${ }^{85}$ Cf., p. ex., RITTER, Adolf Martin. Basilius der Große als "Diakoniker”. In: GÖTZELMANN, Arnd; HERRMANN, Volker; STEIN, Jürgen (Orgs.). Diakonie der Versöhnung: Ethische Reflexion und soziale Arbeit in ökumenischer Verantwortung: Festschrift für Theodor Strohm. Stuttgart: Quell, 1998. (p. 79-93) p. 84 e 90: "Para ele, portanto, a ética dos monges é simplesmente a ética dos cristãos!"

${ }^{86}$ CRISLIP, 2005, p. 129.

${ }^{87}$ KOSCHORKE, 1991, p. 311, enfatizou, entretanto, que as instituições caritativas permaneciam, em última análise, parte do monastério. Toda pessoa que recorresse aos serviços da instituição também precisaria se submeter às regras da communitas.

${ }^{88}$ Cf. mais uma vez Bas., ep. 94.

${ }^{89}$ O próprio Basílio escreveu em ep. 94 (CUFr, v. 1, 205,27-19 C.) de modo bastante críptico sobre a acusação de que uma parte da coletividade era prejudicada pela administração relacionada à igreja.

90 Cf. KNORR, 1968, p. 100, 103s, 113. Também Wolf-Dieter Hauschild supôs que por trás dos conflitos em torno da Basilíada se encontrasse a concorrência entre pagãos e cristãos; cf. BASILIUS, 1990, p. 219, nota 409. 
ascetas radicais como Aério, p. ex. Esse havia entrado em conflito com Eustácio por causa da mistura de "reflexões seculares" e intenções religiosas ${ }^{11}$, concretamente com vistas a uma diaconia institucionalizada. Entretanto, é improvável que ascetas radicais tenham manifestado sua crítica justamente junto ao governador.

Por isso a contestação deve ser localizada, mais provavelmente, em partes da classe alta cristã de Cesareia, que não era de modo algum ascética. Elas se voltavam contra uma penetração forte demais do ideal ascético e bíblico em uma instituição de grande porte concreta, conduzida pela igreja. Em todo caso, essa mistura de ideal religioso e realidade institucional podia se tornar escandalosa tão logo fosse realizada fora dos muros dos conventos. Ela podia implicar uma provocação em duas direções, tanto com vistas aos "doadores" em potencial quando com vistas aos "receptores" de assistência.

Com vistas aos "doadores", Basílio e seus companheiros capadócios radicalizaram a conclamação à partilha e à desistência de posses frente à prática cristã tradicional $^{92}$, como mostrou Adolf Martin Ritter ${ }^{93}$. Neste sentido, a propriedade privada tornou-se praticamente um absurdo ${ }^{94}$, e a pessoa rica foi entendida como "ecônomo dos cosservos" 95 . A partilha coerente dos bens era uma máxima central da ação. Já essa conclamação radical à partilha marcada pelo pensamento monástico de Basílio deve ter topado com incompreensão e também rejeição entre seus contemporâneos.

Mais escandalosa do que as exigências radicais aos "doadores", porém, deve ter sido a compreensão dos "receptores" no caso de Basílio. Essa compreensão estava estreitamente ligada com a dimensão espiritual da instituição. ${ }^{96}$ Gregório de Nissa destacou que Basílio não teria ajudado as pessoas carentes apenas em termos materiais, mas também espirituais: "Por meio de sua boa doutrina, ele tornou os corporalmente pobres em pobres no espírito (sc. das bem-aventuranças); a pobreza deles se lhes tornou uma grande bênção, porque a graça do reino verdadeiro se uniu a ela. E por meio de sua pregação ele fez da alma de cada pessoa uma verdadeira tenda em que Deus habitava, e a dotou de escoras" ${ }^{\text {97 }}$.

Assim, não só a filantropia, a assistência aos pobres e o cuidado dos doentes até então praticados privadamente pelos cristãos foram, segundo Gregório de Nazian-

91 Cf. KOSCHORKE, 1991, p. 309.

92 A conclamação para o apoio aos pobres e, com isso, também para abrir mão de posses dirigida aos ricos era um elemento cristão comum e disseminado em todas as regiões do cristianismo da Antiguidade; cf., p. ex., a $20^{\mathrm{a}}$ instrução de Afraate do ano 344 d.C., cuja versão em alemão se encontra em APHRAHAT. Unterweisungen: Zweiter Teilband, aus dem Syrischen übersetzt und eingeleitet von P. Bruns. Freiburg, 1991. p. 460-474.

93 Cf. a contribuição de RITTER, 1998, que fala, entre outras coisas, de uma “ordem 'comunista' da propriedade" como ideal de Basílio, que deveria ser entendida a partir de sua atitude básica de caráter monástico (p. 81).

${ }^{94}$ Quanto à forma de Basílio lidar com a riqueza, cf., entre outros, Bas., Homilia in divites (PG 31, 277C-304C Migne). O que Basílio visa substancialmente aqui é que a riqueza não seja acumulada, mas empregada para adquirir tesouros no reino dos céus.

95 Cf. Bas., Homilia in Lucam 12,18 2 (PG 31, 24C Migne): oikonómos tôn homodoúlon.

96 Cf. principalmente VISCHER, 1953, p. 142.

97 Gregório de Nissa, In Basilium fratrem (127,20-128,4 L.). A versão em alemão se encontra em VISCHER, 1953 , p. 142 e foi levemente corrigida. 
zo, ligados à categoria clássica do "belo" (kalón) $)^{98}$. Uma ideia dessas deve ter sido escandalosa ou, ao menos, incomum não só para um platônico pagão, mas também para alguns cristãos. A doença e a pobreza não foram mais classificadas negativamente no âmbito amplo e público. ${ }^{99} \mathrm{O}$ tratamento institucionalizado dos doentes não visava mais, como até então, exclusivamente à utilidade social. Antes, no doente, pobre e forasteiro a pessoa se encontrava com Deus. ${ }^{100}$ Segundo Gregório de Nazianzo, com seu engajamento Basílio não teria mais excluído nem mesmo pessoas leprosas das cidades e casas, mas as integrado na sociedade. ${ }^{101}$ Gregório inclusive apresentou Basílio como exemplo, pois ele teria beijado as pessoas que sofriam de lepra. ${ }^{102}$ Doentes, pobres e forasteiros teriam sido respeitados como seres humanos por ele ou em seu grande projeto para não causar ignomínia a Cristo por causa da exclusão deles. O próprio Basílio escreveu que todas as pessoas teriam por natureza a mesma dignidade, independentemente de suas posses e sua posição social. O fator decisivo para posições de destaque seria, antes, o temor de Deus. As pessoas deveriam se encontrar umas com as outras em consonância com isso. ${ }^{103}$ Por isso o grande projeto diaconal e caritativo de Basílio não constituía uma nódoa em que os doentes e marginalizados se concentrassem fora da sociedade, e sim o tesouro genuíno dela. ${ }^{104} \mathrm{O}$ próprio Basílio provavelmente também se referiu nesse sentido à sua instituição como "adorno para o lugar"105.

98 Em Gr. Naz., or. 14,2 (PG 35, 859B M.), Gregório designa a hospitalidade como algo belo (kalón), e em Gr. Naz., or. 14,2 (PG 35, 859B M.) a prática de obras de amor como bela de modo geral.

99 Essa é também a direção da argumentação de CRISLIP, 2005, p. 118-120, que fala da "desestigmatização da doença”. Essa “desestigmatização", porém, não é uma característica do monaquismo, como afirma o autor à p. 137, e sim simplesmente algo que já se encontra no Novo Testamento.

${ }^{100}$ Algo semelhante pode ser observado, tendo Mt 25.35-40 como pano de fundo, também, entre outras passagens, na descrição da beneficência de Pamáquio; cf. Jerônimo, ep. 66,5 (CSEL, 2. ed., 54, 653,3-5 Hilberg).

${ }^{101}$ CRISLIP, 2005, p. 135s, vê um modelo para a forma de Basílio lidar com pessoas leprosas já nos monastérios dos pacomianos.

${ }^{102} \mathrm{Cf}$. de modo semelhante, posteriormente, o relato de Jerônimo sobre Fabíola, que acolhia os doentes de lepra e tratava deles sem distanciamento (Jerônimo, ep. 77,6 [CSEL 55, 43 Hilberg]). Rábula de Odessa honrava os doentes, de maneira semelhante a Basílio, com um ósculo; cf. BLUM, G. G. Rabbula von Edessa: Der Christ, der Bischof, der Theologe. Louvain, 1969. p. 81. À p. 81, nota 112, Blum interpreta o ósculo com o ósculo da paz da celebração eucarística. Dessa forma, os leprosos seriam lembrados de sua comunhão permanente com a igreja. Até mesmo imperatrizes teriam se aproximado pessoalmente de pessoas leprosas; cf. o relato sobre Placila, a primeira esposa de Teodósio I, em Teodoreto, h.e. V 19,2f. (314,3-13 P.).

${ }^{103}$ Cf. Bas., ep. 262,1 (CUFr, Bd. 3, 119,4-8 C.). Com essas afirmações Basílio anima concretamente o monge Urbício a recorrer a ele sem falsa timidez. Cf. também Bas., moral. 45,1 (PG 31, 764D Migne) ou GIET, 1941, p. 41.

${ }^{104} \mathrm{Cf}$. Gr. Naz., or. 43,63, onde consta tò tês eusebeías tamieîon, tò koinòn tôn echónton thesaúrisma (SC 384,262 B.). Cf. também a ideia de que os pobres são o verdadeiro tesouro da igreja na lenda de Laurêncio relatada em Ambr., off. II 28,140 (CChr.SL 15, 148,45-55 Testard).

${ }^{105}$ Cf. Bas., ep. 94 (CUFr, Bd. 1, 206,43s C.): tô tópo kósmos. Em Basílio, ao menos, não se encontra outra fundamentação da razão pela qual ela seria um adorno. 
Segundo Gregório, na Basilíada a doença era vista, assim, à luz da filosofia - isto é, neste caso, cristã ${ }^{106}$-, o infortúnio era entendido como bênção e a empatia era testada. ${ }^{107}$ Em nossa linguagem, deve-se falar de uma inversão dos valores ${ }^{108}$, da integração coerente de máximas bíblicas e da imagem bíblica do ser humano em um projeto diaconal e caritativo de grande porte. ${ }^{109}$

\section{Conclusão}

Portanto o aspecto especial do instituto de Basílio, que faz Gregório falar de "maravilha do mundo", não deve, segundo as afirmações de seus contemporâneos, ter residido nas dimensões da Basilíada (conforme Lukas Vischer ${ }^{110}$ ), nem em formas supostamente bem novas de assistência institucional aos pobres (conforme Koschor$\mathrm{ke}^{111}$ ), nem mesmo no estabelecimento de um hospital agora público, que talvez já tenha existido anteriormente em Sebastia. ${ }^{112} \mathrm{O}$ aspecto especial que fez Gregório de Nazianzo falar de uma "maravilha do mundo" residia, isto sim, na associação explícita de instituições já conhecidas com a prática tradicional da vita evangelica, radicalizada por Basílio, e na interpretação cristã da assistência a ela ligada. ${ }^{113}$ A exigência radical que ele formulou aos doadores, mas principalmente também a inversão dos valores ${ }^{114}$, transformou uma instituição para pessoas carentes e excluídas pela sociedade da Antiguidade em um "adorno para o lugar" e até, por assim dizer, em um lugar de encontro

${ }^{106} \mathrm{Cf}$. quanto ao pano de fundo a noção, existente desde Justino, do cristianismo como filosofia que ajudaria as pessoas inclusive no caminho para Deus; entre outros, HONNEFELDER, Ludger. Christliche Theologie als "wahre Philosophie". In: COLPE, Carsten et al. (Orgs.). Spätantike und Christentum: Beiträge zur Religions- und Geistesgeschichte der griechisch-römischen Kultur und Zivilisation in der Kaiserzeit. Berlin: Akademie-Verlag, 1992. p. 55-75.

${ }^{107}$ Essa empatia, contudo, levava, também segundo Basílio, efetivamente a uma grande recompensa. Assim, ele escreveu, p. ex., em De creatione hominis I 17 (SC 160, 208,6 Smets/van Esbroeck): eàn gene philádelphos, sympathés, homoiótes theô.

${ }^{108}$ Gr. Naz., or. 14,34 (PG 35, 904B M.) fala até de "saúde néscia” e de uma "doença santa”, da "riqueza injusta" e de "pobreza agradecida e sábia (philósophon)".

${ }^{109}$ Cf., p. ex., também Bas., reg. fus. 3,1; 37,1 (1009C-1012A M.). Segundo Bas., reg. br. 155 (1184B M.), o serviço aos doentes nos xenodocheîa deve ser equiparado ao serviço a Cristo.

${ }^{110}$ Cf. VISCHER, 1953, p. 143.

${ }^{111}$ KOSCHORKE, 1991, p. 306.

${ }^{112}$ A tentativa de avaliar as instituições, p. ex. na área hospitalar primordialmente, do ponto de vista da história das instituições, como novidade introduzida pelo cristianismo deve, em última análise, ser insuficiente; cf., p. ex., HARIG, 1971, p. 179-195, em confrontação com Theodor Meyer-Steineg. Na p. 180.

${ }^{113} \mathrm{Cf}$. de modo semelhante e em geral quanto à beneficência na Antiguidade tardia, SCHNEEMELCHER, 1965, p. 67, segundo o qual determinadas formas da atividade caritativa na igreja antiga já foram assumidas do judaísmo e paganismo.

${ }^{114}$ Em Hp., De Arte 3,2, do século IV (Sammlung Tusculum, 108 Schubert/Leschhorn), doentes incuráveis, p. ex., eram excluídos do tratamento médico, ao passo que Basílio justamente os integrava e tratava como seres humanos. No escrito de Hipócrates, por outro lado, nem sequer se fala de assistência neste caso. Platão inclusive rejeita, evocando Asclépio e seus filhos, um cuidado adicional no caso de uma impossibilidade de recuperação da capacidade de desempenho; cf., entre outras passagens, P1., R. 407d-e; 408b (Platon, Werke in acht Bänden 4, 246 Chambry/Schleiermacher). Também no judaísmo pessoas leprosas foram separadas da comunidade por sacerdotes; cf., entre outras passagens, Lv 13s; Nm 5.2; 12.10-15. 
com Deus. A "maravilha do mundo" louvada por Gregório consistia na integração da interpretatio christiana da fraqueza e doença em uma grande instituição. Na associação da imagem cristã do ser humano com uma instituição pública de assistência se encontrava, ao mesmo tempo, uma guinada notável na história da cultura. ${ }^{15}$

\section{Referências}

Edições de textos antigos:

CChr.SG: Corpus Christianorum - Series Graeca

CIJ: Corpus inscriptionum Judaicarum

CSCO: Corpus scriptorium Christianorum orientalium

CUFr: Collection des Universités de France

GCS: Die griechischen christlichen Schriftsteller der ersten drei Jahrhunderte

GNO: Gregorii Nysseni Opera

PG: Patrologiae cursus completus. Acurrante Jacques-Paul Migne. Series Graeca.

SC: Sources chrétiennes

STGL: Studien zur Theologie des geistlichen Lebens

TaS: Texts and studies (Cambridge)

APHRAHAT. Unterweisungen. Zweiter Teilband, aus dem Syrischen übersetzt und eingeleitet von P. Bruns. Freiburg, 1991.

BACHT, Heinrich. Das Vermächtnis des Ursprungs. Würzburg: Echter, 1983. (Studien zum frühen Mönchtum, v. 2: Pachomius - der Mann und sein Werk).

BASILIUS VON CAESAREA. Briefe: übersetzt, eingeleitet und erläutert von W.-D. Hauschild. Stuttgart: Revue des Sciences philosophiques et théologiques, 1990.

BLUM, G. G. Rabbula von Edessa: Der Christ, der Bischof, der Theologe. Leuven: Peeters, 1969. CHITTY, Derwas J. The Desert a City: An Introduction to the Study of Egyptian and Palestinian Monasticism under the Christian Empire. Oxford: Blackwell, 1966.

COLUMELLA. Zwölf Bücher über Landwirtschaft. Buch eines Unbekannten über Baumzüchtung, hg. und übersetzt von W. Richter. Darmstadt: Wissenschaftliche Buchgesellschaft, 1982. Bd. 3.

CRISLIP, Andrew. T. From Monastery to Hospital: Christian Monasticism and the Transformation of Health Care in Late Antiquity. Ann Arbor : University of Michigan, 2005.

GIET, Stanislas. Les idées et l'action sociales de Saint Basile. Paris: Lecoffre, 1941.

GOEHRING, James E. Withdrawing from the Desert: Pachomius and the Development of Village Monasticism in Upper Egypt. Harvard Theological Review, v. 89, p. 267-285, 1996.

GROSSMANN, Peter. Christliche Architektur in Ägypten. Leiden: Brill, 2002.

HARIG, G. Zum Problem "Krankenhaus” in der Antike. Klio, v. 53, 1971.

HILD, Friedrich; RESTLE, Marcell (Orgs.). Kappadokien (Kappadokia, Charsianon, Sebasteia und Lykandos). Wien: Verlag der Österreichischen Akademie der Wissenschaften, 1981.

HILTBRUNNER, Otto. Krankenhaus. In: Reallexikon für Antike und Christentum. Stuttgart: Hiersemann, 2006. v. 21, col. 882-914.

${ }^{115}$ RITTER, 1998, p. 85, diz que a velha atividade caritativa cristã teria adquirido pela primeira vez "dimensões "medievais", mas marcada por um espírito monacal. Uhlhorn não vê nos hospitais, como muitas vezes se veicula, simplesmente apenas uma consequência do esfriamento da atividade caritativa. Os hospitais teriam, isto sim, se tornado uma necessidade e levados a se tornar instituições pela pressão da época; cf. UHLHORN, 1895, p. 194s. 
HONNEFELDER, Ludger. Christliche Theologie als "wahre Philosophie". In: COLPE, Carsten et al. (Orgs.). Spätantike und Christentum: Beiträge zur Religions- und Geistesgeschichte der griechischrömischen Kultur und Zivilisation in der Kaiserzeit. Berlin: Akademie-Verlag, 1992. p. 55-75.

KISLINGER, Ewald. Kaiser Julian und die (christlichen) xenodocheia. In: HÖRANDNER, Wolfram et al. (Orgs.). Byzantios: Festschrift für Herbert Hunger zum 70. Geburtstag. Wien: Becvar, 1984. p. 171-184.

KISLINGER, Ewald. Hospital, II. Byzantinisches Reich. In: Lexikon des Mittelalters. 1991. v. 5. KNORR, Uwe W. Basilius der Große: Sein Beitrag zur christlichen Durchdringung Kleinasiens. 1968. Tese (Doutorado) - Tübingen, 1968. 2 v.

KOSCHORKE, Klaus. Spuren der alten Liebe: Studien zum Kirchenbegriff des Basilius von Caesarea. Freiburg (Schweiz): Universitätsverlag, 1991.

KRAUSE, Martin. Das Mönchtum in Ägypten. In: (Org.). Ägypten in spätantikchristlicher Zeit: Einführung in die koptische Kultur. Wiesbaden: Reichert, 1998. p. 149-174. KÜCHLER, Max. Jerusalem: Ein Handbuch und Studienreiseführer zur Heiligen Stadt. Göttingen: Vandenhoeck \& Ruprecht, 2007.

MEYER, Philipp. Aërius. In: Realenzyclopädie für protestantische Theologie und Kirche. 3. ed. Leipzig: Hinrichs, 1896. v. 1, p. 232s.

MÜLLER, Andreas. Die Christianisierung staatlicher Wohlfahrtsinstitutionen im spätantiken Rom am Beispiel von S. Maria in Cosmedin. Zeitschrift für Kirchengeschichte, v. 120, p. 160-186, 2009. PETRIKOVITS, Harald von. Die Innenbauten römischer Legionslager während der Prinzipatszeit. Opladen: Westdeutscher Verlag, 1975.

PHILIPSBORN, Alexander. Der Fortschritt in der Entwicklung des byzantinischen Krankenhauswesens. Byzantinische Zeitschrift, v. 54, p. 338-365, 1961.

PUZICHA, Michaela. Christus peregrinus: Die Fremdenaufnahme (Mt 25,35) als Werk der privaten Wohltätigkeit im Urteil der Alten Kirche. Münster: Aschendorff, 1980.

RESTLE, Marcell. Studien zur frühbyzantinischen Architektur Kappadokiens. Wien: Verlag der Österreichischen Akademie der Wissenschaften, 1979. v. 1.

RITTER, Adolf Martin. Basilius der Große als “Diakoniker”. In: GÖTZELMANN, Arnd; HERRMANN, Volker; STEIN, Jürgen (Orgs.). Diakonie der Versöhnung: Ethische Reflexion und soziale Arbeit in ökumenischer Verantwortung: Festschrift für Theodor Strohm. Stuttgart: Quell, 1998. ROUSSEAU, Philip. Basil of Caesarea. Berkeley: University of California, 1994.

.Pachomius: The Making of a Community in Fourth-Century Egypt. Berkeley: University of California, 1985.

SAVRAMIS, Demosthenes. Zur Soziologie des byzantinischen Mönchtums. Leiden; Köln: Brill, 1962. SCHNEEMELCHER, Wilhelm. Der Diakonische Dienst in der Alten Kirche. In: KRIMM, Herbert (Org.). Das Diakonische Amt der Kirche. 2. ed. Stuttgart: Evangelisches Verlagswerk, 1965. p. 61-103.

STEIDLE, B. "Ich war krank und ihr habt mich besucht" (Mt 25,36) [I]. Erbe und Auftrag, v. 40, p. 443-458, 1964.

."Ich war krank und ihr habt mich besucht" (Mt 25,36) [II]. Erbe und Auftrag, v. 41, p. 36-46, 99-113, 189-206, 1965.

UHLHORN, Gerhard. Die christliche Liebestätigkeit in der Alten Kirche. 2. ed. Stuttgart, 1895. ; HAUCK, Albert. Wohltätigkeitsanstalten. In: Realenzyclopädie für protestantische

Theologie und Kirche. 3. ed. Leipzig: Hinrichs, 1908. v. 21, p. 435-452.

VISCHER, Lukas. Basilius der Große: Untersuchungen zu einem Kirchenvater des vierten Jahrhunderts. Basel: Friedrich Reinhardt, 1953.

VOLK, Robert. Gesundheitswesen und Wohltätigkeit im Spiegel der byzantinischen Klostertypika. München: Institut für Byzantinistik und neugriechische Philologie der Universität, 1983. 
WACHT, Manfred. Krankenfürsorge. In: Reallexikon für Antike und Christentum. Stuttgart: Hiersemann, 2006. v. 21, col. 826-882.

WILMANNS, Juliane C. Der Sanitätsdienst im Römischen Reich: Eine sozialgeschichtliche Studie zum römischen Militärsanitätswesen nebst einer Prosopographie des Sanitätspersonals. Hildesheim: Olms-Weidmann, 1995. 